\title{
SCIDiC
}

International Journal of Dentistry and Oral Science (IJDOS)

ISSN: 2377-8075

\section{Comparison Of Colour Stability Of Two Commercially Available Glass Ionomer Cements After Im- mersion In Lemon Juice - An In Vitro Study}

Research Article

Kamalli.Mํ. S Jayalakshmi²*, Balaji Ganesh S

${ }^{1}$ Saveetha Dental College and Hospitals, Saveetha Institute of Medical and Technical Sciences (SIMATS), Saveetha University, Chennai- 77, India.

${ }^{2}$ Reader, White Lab- Material Research Centre, Saveetha Dental College and Hospitals, Saveetha Institute of Medical and Technical Sciences [SIMATS], Saveetha University, Chennai- 77, India.

${ }^{3}$ Senior Lecturer, White Lab- Material Research Centre, Saveetha Dental College and Hospitals, Saveetha Institute of Medical and Technical Sciences [SIMATS], Saveetha University, Chennai- 77, India.

\section{Abstract}

Introduction: Glass ionomer cement are aesthetic restorative materials and considered to be one of the best of restorative materials due to high fluoride release and chemical bonding to the tooth structure. They possess high solubility and least compressive strength. The more concentrated sugar and calories in fruit juice can cause discolouration of the tooth surface. In a restored tooth with glass ionomer cement, fruit juice can cause certain effects.

Aim: The aim of the study is to compare the colour stability of two commercially available Glass ionomer cements after immersion in lemon fruit juice.

Materials and Methods: For analysing the colour stability, two different commercially available brands of Glass ionomer cements were taken, then processed and moulded into pellets which were trimmed and polished. The GIC pellets were then labelled with numbers 1 to 10 . The pre-immersion values from the spectrophotometer were noted. Then the GIC pellets were immersed in fruit juice for 24 hours. The values from the spectrophotometer were recorded after immersion in fruit juice. Then the pre-immersion and post-immersion values were compared in order to obtain results. Independent sample $t$ test was used to find the significant difference among the groups.

Results: The mean value of delta-E of pyrax samples was found to be 6.31 and the mean value of delta-E of D-Tech samples was found to be 10.94. The obtained results are statistically not significant as the p-value is $0.108(>0.05)$.

Conclusion: Under the tested experimental conditions, the present study concludes that Pyrax GIC shows more colour stability than D-Tech.

Keywords: Colour Stability; Gic; Innovative Technique; Immersion; Fruit Juice.

\section{Introduction}

Glass ionomer cement are aesthetic restorative materials and considered to be one of the best of restorative materials due to high fluoride release and chemical bonding to the tooth structure. They possess high solubility and least compressive strength. The color, shape and surface of teeth brings a beautiful smile. Color sustainability of glass ionomer cement is important to evaluate the success of the treatment. Fluoride content in GIC stops bacterial growth. Nowadays, modified forms of glass ionomers are comparably better in terms of physical properties [1]. Polymeric water soluble acid, basic glass, and water are the three essential components of glass ionomer cement [2]. Glass ionomer cement takes about 2-3 minutes to set which is by acid-base reaction. Glass ionomer cements possess reasonable flexural strength [3]. Glass ionomer cements were introduced and developed by Wilson and Kent in the 1960s. They chemically bond to the tooth structure and act as one of the best choices for restorative and luting functions. They are commercially available as different types with different functions. The invention and development of nanotechnology in the 21 st century lead to the reinforcement of glass ionomer cements [4].

In previous studies performed, GICs exhibit stability towards in-

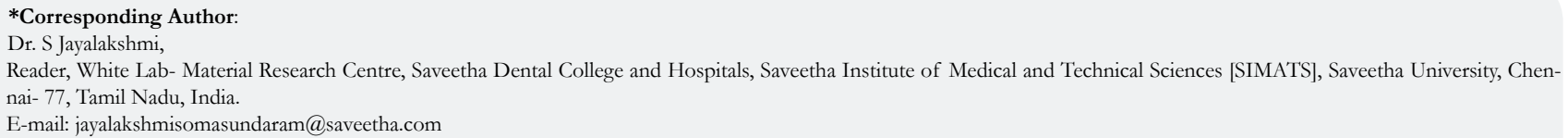

Copyright: Dr. S Jayalakshmi ${ }^{\circ} 2021$. This is an open-access article distributed under the terms of the Creative Commons Attribution License, which permits unrestricted use, distribution and reproduction in any medium, provided the original author and source are credited. 
creased consumption of acidic beverages, yet more research is essential on the effects of these beverages on the colour stability and surface texture of GICs. Glass ionomer cements have been used in restorative dentistry for years now. Their utility in restorative dentistry is comparatively reliable because of their fluoride release, adhesion to tooth structures, and use in a variety of clinical scenarios. Glass ionomer cements are known for prevention of caries through a constant fluoride release for a long period of time and these are more resistant to demineralization. It is said to possess more retention to the tooth structure than the resin based type of sealants. GICs have hydrophilic characteristics making them an alternative of the hydrophobic resin based sealants. Resin-based sealants are destroyed by saliva contamination very easily. When associated with chemical nature, allergic reactions are in association with both sealants in very rare cases [5].

Fruit juices are healthy as they are natural and sweet in taste. Fruit juices are often added with flavours, artificial colours and additives. The more concentrated sugar and calories in fruit juice can cause discolouration of the tooth surface. Frequent consumption of fruit juices may result in adverse effects of tooth structure and colour. Glass ionomer cements are available in different commercial brands. The fluoride content, opaqueness, characterization of each type of GIC varies from brand to brand [6]. Bioactivity, biocompatibility characteristics depend on the type of glass ionomer cement [7]. Strength and stability depends on the elements of glass ionomer cement [8].

Restorative materials tend to have different compositions, surface roughness and texture and stability which decides the longevity of the material [9]. The $\mathrm{pH}$ of the different liquids and foods consumed have great influence in altering the composition and longevity of the restorative material. Juices in general can cause staining which is attributed to the presence of acids like phos- phoric acid, carbonic acid etc. which causes increase or decrease in normal $\mathrm{pH}$ environment [10]. Consumption of juices at regular intervals for over a long period of time can cause visible changes in the appearance of restorative material. In a restored tooth with glass ionomer cement, fruit juice can cause certain effects. In previous research, colour stability of GIC was tested in general. In this study, two different brands of glass Ionomer cements are tested for their colour stability. Also, the effects of fruit juice on glass ionomer cement is also tested. The aim of the study is to compare the colour stability of two commercially available Glass Ionomer cements after immersion in lemon juice.

\section{Materials and Methods}

For analysing the colour stability, two different commercially available brands of Glass ionomer cements (D-Tech and Pyrax) were taken. It was then processed and moulded into pellets of diameter $2 \mathrm{~mm}$. The pellets were trimmed and polished to perfection with trimming and polishing burs. The GIC pellets were then labelled with numbers 1 to 10 (Figure-1). Spectrophotometer-VITA easyshade was used to measure the colour (Figure-2). The pre-immersion values from the spectrophotometer were noted (Figure-3). Then the GIC pellets were immersed in lemon juice for 24 hours (Figure-4). The GIC pellets after immersion were taken to record the post immersion values. Then the pre-immersion and postimmersion values were compared in order to obtain results. The LAB system and protocols were used for colour measurement analysis. This system is most commonly used for colour measurement analysis where ' $\mathrm{L}$ ' stands for colour, 'A' (green/red) and 'B' (yellow/blue) stands as coordinate axes. Delta-E represents a single number which is the distance between two colours. Independent sample t test was used to find the significant difference among the groups. Values $(\mathrm{p}>0.05)$ are considered to be significant.

Figure 1. Figure representing the GIC samples before immersion in lemon juice labelled from 1 to 10 where 1 to 5 labelled GIC samples represent Pyrax brand and 6 to 10 labelled GIC samples represent the D-Tech brand.

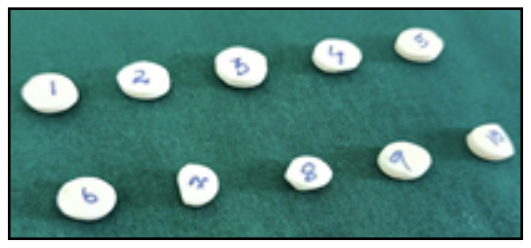

Figure 2. Spectrophotometer which is used for colour measurement and intensity of light.

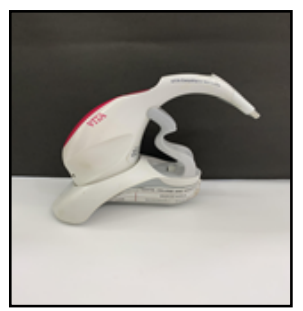

Figure 3. Spectrophotometer measuring the colour of the GIC samples before immersion.

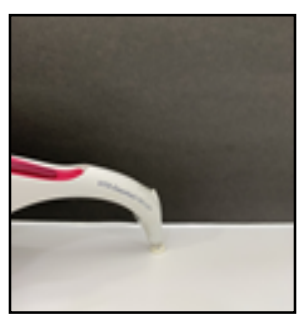


Figure 4. Figure representing the GIC samples immersed in lemon juice for 24 hours.

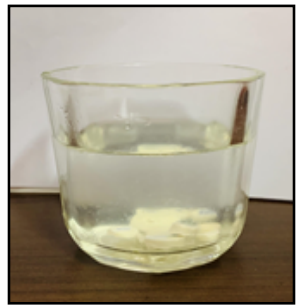

Figure 5. Bar graph depicting the Delta E mean value for the GIC samples from Pyrax and D-Tech immersed in fruit juice for 24 hours where $X$ axis represents the GIC samples and $Y$ axis represents the mean values. The colour blue represents Pyrax and orange represents D Tech. The mean value for Pyrax is 6.310 The mean value for D Tech is 10.941. With comparison of mean values, Pyrax shows more colour stability. The p-value obtained is $0.108(p>0.05)$ which is statistically not significant.

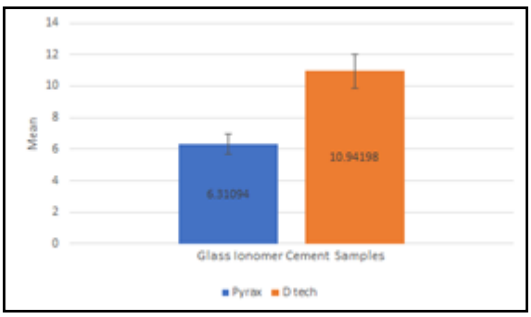

Table 1. Pre-immersion and Post-immersion values for the samples from Pyrax by spectrophotometer.

\begin{tabular}{|c|c|c|c|c|c|c|}
\hline Pyrax & \multicolumn{3}{|c|}{ Pre-immersion values } & \multicolumn{3}{c|}{ Post-immersion values } \\
\hline Values & L & A & B & L & A & B \\
\hline 1 & 89.9 & -2 & 15.8 & 92 & -0.4 & 18 \\
\hline 2 & 90.3 & -0.8 & 14.2 & 83.7 & 0 & 10.4 \\
\hline 3 & 92.3 & -0.9 & 16.3 & 86.6 & 0.1 & 13 \\
\hline 4 & 87 & -0.6 & 11.7 & 88.1 & -0.6 & 16.4 \\
\hline 5 & 86 & -0.9 & 11.3 & 93.3 & -0.5 & 16.5 \\
\hline
\end{tabular}

Table 2. Pre-immersion and Post-immersion values for the samples from D-Tech by spectrophotometer.

\begin{tabular}{|c|c|c|c|c|c|c|}
\hline D-Tech & \multicolumn{3}{|c|}{ Pre-immersion values } & \multicolumn{3}{c|}{ Post-immersion values } \\
\hline Values & L & A & B & L & A & B \\
\hline 6 & 95.3 & -1.2 & 24.3 & 89.7 & 0.8 & 19.7 \\
\hline 7 & 98 & -0.6 & 24.3 & 84.8 & -0.3 & 13.7 \\
\hline 8 & 97.9 & & 15.8 & 100 & 0.4 & 7.9 \\
\hline 9 & 93.9 & -1.1 & 24 & 100 & 0.1 & 12.4 \\
\hline 10 & 80.6 & -1.1 & 11.6 & 88.3 & 0.1 & 15.7 \\
\hline
\end{tabular}

Table 3. Delta E values for the samples from Pyrax and D-Tech.

\begin{tabular}{|c|c|}
\hline Delta-E & Delta-E \\
\hline Pyrax & D-Tech \\
\hline 3.437 & 7.518 \\
\hline 7.658 & 16.932 \\
\hline 6.662 & 8.293 \\
\hline 4.827 & 13.161 \\
\hline 8.972 & 8.806 \\
\hline
\end{tabular}


Table 4. Table showing the mean and standard deviation of colour stability between the two groups.

\begin{tabular}{|c|c|c|c|c|}
\hline Groups (Delta-E) & N & Mean & Standard Deviation & P value \\
\hline Pyrax & 5 & 6.311 & 2.207 & \multirow{2}{*}{0.108} \\
\hline D tech & 5 & 10.942 & 4.003 & \\
\hline
\end{tabular}

Independent sample $t$ test was used.

\section{Results}

In the present study, two different Glass Ionomer cements were analysed for colour stability after immersion in lemon juice for 24 hours. The L, A and B values of the samples were recorded using a spectrophotometer before immersion in fruit juice. Then the samples were immersed in fruit juice for 24 hours. The L, A and $B$ values which is the system most commonly used for colour measurement analysis where 'L' stands for colour, 'A' (green/red) and 'B' (yellow/blue) stands as coordinate axes. were recorded after immersion. The pre immersion and post immersion values were tabulated for comparison (Table-1 and Table-2). The delta E values were obtained for each sample and noted (Table-3).

Generally, the delta-E value is used to assess the colour stability of samples. The mean value for delta $E$ values was statistically analysed using SPSS software and depicted in the form of a bar graph (Figure-6). The p-value was evaluated to assess the significance of the results obtained. The mean value of delta-E of pyrax samples was found to be 6.31 and the mean value of delta-E of D-Tech samples was found to be 10.94. The Mean and standard deviation of colour stability between the two commercially available GIC brands were determined (Table-4). With comparison of mean values, Pyrax shows more colour stability. The $\mathrm{p}$-value obtained is $0.108(\mathrm{p}>0.05)$ which is statistically not significant.

\section{Discussion}

Increased urban development has led the people to move away from cooking and pushed to consumption of processed food and beverages which constitute a wide range of coloring agents, sweeteners that not only increases the risk of obesity, cardiovascular diseases and various health problems but also has negative effect on the color stability of the aesthetic restorative materials. Henceforth, the aim of the present study is to evaluate the color stability of two different commercially available GIC when immersed in fruit juices. The oral cavity is exposed to a variety of organic and inorganic substances on a day to day basis in which many substances can cause staining or cause alterations in the surface of dental restorations causing degradation and affecting the aesthetics. Staining can also be influenced by dietary factors. Many studies were done on the staining effects of beverages on tooth-colored restorations and checking the colour stability. In the present study, the effect of fruit juices on glass ionomer cement restorative material as the consumption of fruit juices and soft drinks has increased in recent years among children and young adults.

The L A B color axes is used for the measurement of color change universally and considered to be a better method than subjective methods for assessment of colour change [11]. $\Delta \mathrm{E}$ value is currently used to assess the colour stability for comparison between different restorative materials [12]. The mean value of delta-E of pyrax samples was found to be 6.31 and the mean value of delta$\mathrm{E}$ of $\mathrm{D}$-Tech samples was found to be 10.94. Delta-E value is used to assess the colour stability of samples. If the value is below 2.5 , then the sample is found to be resistant to colour changes. If the values are between 2.5 to 10 , then the sample is found to have moderate colour changes. The sample is found to show high variations in colour if the value is above 10 . With assessment and comparison of mean delta-E values, pyrax is found to have moderate colour changes and D-Tech is found to show high variations in colour. The $\mathrm{p}$-value is $0.108(\mathrm{p}>0.05)$ which is statistically not significant.

In the study by Hotwani et al., it was inferred that giomer samples exhibited comparatively less color change to RMGIC samples indicating better color stability. The maximum color changes were observed for a span of 4 weeks by consuming coke [13]. In the study by Janhnvi et al., Glass ionomer samples from GC Solarescupt brand had the least color resistance due to increased content of resin and comparatively high porosity. In a previous study, in an oral environment where solutions and other beverages consumed were combined with saliva, it dilutes their concentration and causes change in $\mathrm{pH}$ which influences the change in colour of restoration [14]. In the present study, an undiluted solution is used to avoid any variations. In the study by Asmussen $\mathrm{E}$ et al., restorations can show differences in colour according to variations and are completely subjected to the type of restoration used [15]. Staining of restorative materials might include factors like degree of water absorption of material meaning the absorbance of fluids like water, tea, coffee and juices [16].

Our team has extensive knowledge and research experience that has translated into high quality publications [17-36]. The limitations of the study is that only limited samples from two commercially available GIC brands were used to perform the experiment. The immersion was done for only 24 hours. This is an in vitro study where the $\Delta \mathrm{E}$ values may be increased as the role of saliva in bringing the long-term accumulation of stains in the oral cavity cannot be simulated. However, further studies need to be carried out to evaluate the water absorption, and dissolution and surface irregularities of this restorative glass ionomer cement using different temperatures and $\mathrm{pH}$ as variables. The main aim of this study will aid dental professionals to guide patients about the staining characteristics of various beverages on glass ionomer cement and other tooth coloured restorative materials and recommend them to avoid such beverages at a regular frequency. However, there are various other factors which influence the colour change that should be focused and taken into account in further studies.In future studies, more commercially available GIC brands can be compared to assess the colour stability and to obtain significant results. 


\section{Conclusion}

Under the tested experimental conditions, the present study concludes that Pyrax GIC shows more colour stability than D-Tech. With assessment and comparison of mean delta-E values, Pyrax is found to have moderate colour changes and D-Tech is found to show high variations in colour.

\section{Acknowledgement}

This research was done under the supervision of the Department of Research of Saveetha Dental College and Hospitals. We sincerely show gratitude to the corresponding guides who provided insight and expertise that greatly assisted the research.

\section{Source of Funding}

- Saveetha Dental College and Hospitals, Saveetha Institute of Medical and Technical Sciences, Saveetha University, Chennai

- Molequle Solutions, Chennai.

\section{References}

[1]. Sidhu SK, Nicholson JW. A review of glass-ionomer cements for clinical dentistry. J Funct Biomater. 2016 Sep;7(3):16.

[2]. Tyas MJ. Clinical evaluation of glass-ionomer cement restorations. J. Appl. Oral Sci. 2006;14:10-3.

[3]. Choi K, Oshida Y, Platt JA, Cochran MA, Matis BA, Yi K. Microtensile bond strength of glass ionomer cements to artificially created carious dentin. Oper Dent. 2006 Sep;31(5):590-7.

[4]. Berg JH, Croll TP. Glass ionomer restorative cement systems: an update. Pediatr Dent. 2015 Apr 15;37(2):116-24.

[5]. Al-Samadani KH. Color stability of restorative materials in response to Arabic coffee, Turkish coffee and Nescafe. J Contemp Dent Pract. 2013 Jul 1;14(4):681-90.Pubmed PMID: 24309349.

[6]. Khaghani M, Doostmohammadi A, Golniya Z, Monshi A, Arefpour AR. Preparation, physicochemical characterization, and bioactivity evaluation of strontium-containing glass ionomer cement. Int Sch Res Notices. 2013;2013:1-7.

[7]. Neelakantan P, John S, Anand S, Sureshbabu N, Subbarao C. Fluoride release from a new glass-ionomer cement. Oper Dent. 2011 Jan;36(1):80-5.

[8]. Gjorgievska E, Nicholson JW, Gabrić D, Guclu ZA, Miletić I, Coleman NJ. Assessment of the Impact of the Addition of Nanoparticles on the Properties of Glass-Ionomer Cements. Materials (Basel). 2020 Jan 8;13(2):276.Pubmed PMID: 31936253.

[9]. Samra AP, Pereira SK, Delgado LC, Borges CP. Color stability evaluation of aesthetic restorative materials. Braz Oral Res. 2008 Sep;22(3):205-10.

[10]. Adusumilli H, Avula JS, Kakarla P, Bandi S, Mallela GM, Vallabhaneni K. Color stability of esthetic restorative materials used in pediatric dentistry: An in vitro study. J Indian Soc Pedod Prev Dent. 2016 Jul 1;34(3):233.

[11]. Gómez-Polo C, Muñoz MP, Luengo MC, Vicente P, Galindo P, Casado AM. Comparison of the CIELab and CIEDE2000 color difference formulas. J. Prosthet. Dent.. 2016 Jan 1;115(1):65-70.

[12]. Kirchner E, Koeckhoven P, Sivakumar K. Predicting the performance of low-cost color instruments for color identification. JOSA A. 2019 Mar 1;36(3):368-76.

[13]. Hotwani K, Thosar N, Baliga S. Comparative in vitro assessment of color stability of hybrid esthetic restorative materials against various children's beverages. J Conserv Dent. 2014 Jan;17(1):70-4.Pubmed PMID: 24554866.

[14]. Tunc ES, Bayrak S, Guler AU, Tuloglu N. The effects of children's drinks on the color stability of various restorative materials. J. Clin. Pediatr. Dent. 2009 Dec 1;34(2):147-50.

[15]. Asmussen E, Hansen EK. Surface discoloration of restorative resins in relation to surface softening and oral hygiene. Scand J Dent Res. 1986 Apr;94(2):174-7.Pubmed PMID: 2939546.

[16]. Bagheri R, Burrow MF, Tyas M. Influence of food-simulating solutions and surface finish on susceptibility to staining of aesthetic restorative materials. J Dent. 2005 May;33(5):389-98.Pubmed PMID: 15833394.
[17]. Muthukrishnan L. Imminent antimicrobial bioink deploying cellulose, alginate, EPS and synthetic polymers for 3D bioprinting of tissue constructs. Carbohydr Polym. 2021 May 15;260:117774.Pubmed PMID: 33712131.

[18]. PradeepKumar AR, Shemesh H, Nivedhitha MS, Hashir MMJ, Arockiam S, Uma Maheswari TN, et al. Diagnosis of Vertical Root Fractures by Conebeam Computed Tomography in Root-filled Teeth with Confirmation by Direct Visualization: A Systematic Review and Meta-Analysis. J Endod. 2021 Aug;47(8):1198-1214.Pubmed PMID: 33984375.

[19]. Chakraborty T, Jamal RF, Battineni G, Teja KV, Marto CM, Spagnuolo G. A Review of Prolonged Post-COVID-19 Symptoms and Their Implications on Dental Management. Int J Environ Res Public Health. 2021 May 12;18(10):5131.Pubmed PMID: 34066174.

[20]. Muthukrishnan L. Nanotechnology for cleaner leather production: a review. Environmental Chemistry Letters. 2021 Jan 13;19(3):2527-49.

[21]. Teja KV, Ramesh S. Is a filled lateral canal - A sign of superiority? J Dent Sci. 2020 Dec;15(4):562-563.Pubmed PMID: 33505634.

[22]. Narendran K, MS N, SARVANAN A, SUKUMAR E. Synthesis, Characterization, Free Radical Scavenging and Cytotoxic Activities of Phenylvilangin, a Substituted Dimer of Embelin. Indian J. Pharm. Sci. 2020 Sep 1;82(5).

[23]. Reddy P, Krithikadatta J, Srinivasan V, Raghu S, Velumurugan N. Dental Caries Profile and Associated Risk Factors Among Adolescent School Children in an Urban South-Indian City. Oral Health Prev Dent. 2020 Apr 1;18(1):379-386.Pubmed PMID: 32618460.

[24]. Sawant K, Pawar AM, Banga KS, Machado R, Karobari MI, Marya A, et al. Dentinal Microcracks after Root Canal Instrumentation Using Instruments Manufactured with Different NiTi Alloys and the SAF System: A Systematic Review. Appl. Sci. 2021 Jan;11(11):4984.

[25]. Bhavikatti SK, Karobari MI, Zainuddin SLA, Marya A, Nadaf SJ, Sawant VJ, et al. Investigating the Antioxidant and Cytocompatibility of Mimusops elengi Linn Extract over Human Gingival Fibroblast Cells. Int J Environ Res Public Health. 2021 Jul 4;18(13):7162.Pubmed PMID: 34281099.

[26]. Karobari MI, Basheer SN, Sayed FR, Shaikh S, Agwan MAS, Marya A, et al. An In Vitro Stereomicroscopic Evaluation of Bioactivity between Neo MTA Plus, Pro Root MTA, BIODENTINE \& Glass Ionomer Cement Using Dye Penetration Method. Materials (Basel). 2021 Jun 8;14(12):3159.Pubmed PMID: 34201321.

[27]. Rohit Singh T, Ezhilarasan D. Ethanolic Extract of Lagerstroemia Speciosa (L.) Pers., Induces Apoptosis and Cell Cycle Arrest in HepG2 Cells. Nutr Cancer. 2020;72(1):146-156.Pubmed PMID: 31149840.

[28]. Ezhilarasan D. MicroRNA interplay between hepatic stellate cell quiescence and activation. Eur J Pharmacol. 2020 Oct 15;885:173507.Pubmed PMID: 32858048.

[29]. Romera A, Peredpaya S, Shparyk Y, Bondarenko I, Bariani GM, Abdalla $\mathrm{KC}$, et al. Bevacizumab biosimilar BEVZ92 versus reference bevacizumab in combination with FOLFOX or FOLFIRI as first-line treatment for metastatic colorectal cancer: a multicentre, open-label, randomised controlled trial. Lancet Gastroenterol Hepatol. 2018 Dec 1;3(12):845-55.

[30]. Raj R K, D E, S R. ख-Sitosterol-assisted silver nanoparticles activates Nrf2 and triggers mitochondrial apoptosis via oxidative stress in human hepatocellular cancer cell line. J Biomed Mater Res A. 2020 Sep;108(9):18991908.Pubmed PMID: 32319188.

[31]. Vijayashree Priyadharsini J. In silico validation of the non-antibiotic drugs acetaminophen and ibuprofen as antibacterial agents against red complex pathogens. J Periodontol. 2019 Dec;90(12):1441-1448.Pubmed PMID: 31257588.

[32]. Vijayashree Priyadharsini J, Smiline Girija AS, Paramasivam A. In silico analysis of virulence genes in an emerging dental pathogen A. baumannii and related species. Arch Oral Biol. 2018 Oct;94:93-98.Pubmed PMID: 30015217.

[33]. Uma Maheswari TN, Nivedhitha MS, Ramani P. Expression profile of salivary micro RNA-21 and 31 in oral potentially malignant disorders. Braz Oral Res. 2020 Feb 10;34:e002.Pubmed PMID: 32049107.

[34]. Gudipaneni RK, Alam MK, Patil SR, Karobari MI. Measurement of the Maximum Occlusal Bite Force and its Relation to the Caries Spectrum of First Permanent Molars in Early Permanent Dentition. J Clin Pediatr Dent. 2020 Dec 1;44(6):423-428.Pubmed PMID: 33378468.

[35]. Chaturvedula BB, Muthukrishnan A, Bhuvaraghan A, Sandler J, Thiruvenkatachari B. Dens invaginatus: a review and orthodontic implications. Br Dent J. 2021 Mar;230(6):345-350.Pubmed PMID: 33772187.

[36]. Kanniah P, Radhamani J, Chelliah P, Muthusamy N, Joshua Jebasingh Sathiya Balasingh Thangapandi E, Reeta Thangapandi J, et al. Green synthesis of multifaceted silver nanoparticles using the flower extract of Aerva lanata and evaluation of its biological and environmental applications. ChemistrySelect. 2020 Feb 21;5(7):2322-31. 